\title{
Violence against healthcare workers and other serious responses to medical disputes in China: surveys of patients at 12 public hospitals
}

Yuxian Du ${ }^{1,2}$, Wenxin Wang ${ }^{3 *}$, David J. Washburn ${ }^{4}$, Shinduk Lee ${ }^{5}$, Samuel D. Towne Jr ${ }^{5,6,7,8,9}$, Hao Zhang ${ }^{4}$ and Jay E. Maddock ${ }^{*^{*}}$

\begin{abstract}
Background: Workplace violence against healthcare workers is a global issue that is on the rise, with Chinese healthcare workers facing growing challenges with hospital violence. Attacks on medical staff have increased in recent years with no clear resolution. Prior research focused on policies to improve the doctor-patient relationship and better protect clinicians, but few studies addressed the patient perspective. This paper examines patients' choices when facing a medical dispute and identifies groups who are more likely to respond to conflict with violence or other serious actions.

Methods: Patient survey responses were collected in 12 leading public hospitals in five Chinese provinces with 5556 participants. The survey asked sociodemographic information, patients' attitudes (e.g., general optimism, trust in their physicians, perceived healthcare quality), and their primary response to a medical dispute. From least to most severe, the options range from "complaining within the family" to "violence." We used t-tests and Chi-square tests to explore the relationships between reactions and patient characteristics. We also performed multivariable logistic regressions to determine the impact of sociodemographics and provider trust on the seriousness of responses.
\end{abstract}

Results: The primary response of a third of respondents was complaining to hospital or health department officials (32.5\%). Seeking legal help (26.3\%) and direct negotiation with doctors (19.6\%) were other frequent responses. More serious responses included 83 stating violence (1.5\%), 9.7\% expressing a desire to expose the issue to the news media, and $7.4 \%$ resorting to seeking third-party assistance. Patients who were more likely to report "violence" were male $(\mathrm{OR}=1.81, p<.05)$, high-income earners $(\mathrm{OR}=3.71, p<.05)$, or reported lower life satisfaction $(\mathrm{OR}=1.40$, $p<.05)$. Higher trust scores were associated with a lower likelihood of a serious response, including violence $(\mathrm{OR}=$ $0.80, p<.01)$.

*Correspondence: wxwang666@126.com; maddock@tamu.edu

${ }^{3}$ Department of Public Administration, Law School, Shantou University, Shan-Tou 515063, People's Republic of China

${ }^{8}$ Department of Environmental and Occupational Health, School of Public Health, Texas A\&M University, College Station, TX 77843, USA

Full list of author information is available at the end of the article

(c) The Author(s). 2020 Open Access This article is licensed under a Creative Commons Attribution 4.0 International License, which permits use, sharing, adaptation, distribution and reproduction in any medium or format, as long as you give appropriate credit to the original author(s) and the source, provide a link to the Creative Commons licence, and indicate if changes were made. The images or other third party material in this article are included in the article's Creative Commons licence, unless indicated otherwise in a credit line to the material. If material is not included in the article's Creative Commons licence and your intended use is not permitted by statutory regulation or exceeds the permitted use, you will need to obtain permission directly from the copyright holder. To view a copy of this licence, visit http://creativecommons.org/licenses/by/4.0/ The Creative Commons Public Domain Dedication waiver (http://creativecommons.org/publicdomain/zero/1.0/) applies to the data made available in this article, unless otherwise stated in a credit line to the data. 


\begin{abstract}
(Continued from previous page)
Conclusion: Most respondents reported mild reactions when facing a medical dispute. Among those who reported the intent of serious reactions, some sociodemographic characteristics and the trust of physicians could be predictive. To prevent future hospital violence, this work helps identify the characteristics of patients who are more likely to seek severe approaches to medical dispute resolution, including resorting to violence. From these results, hospitals will be better able to target specific groups for interventions that build patient-provider trust and improve general patient satisfaction.
\end{abstract}

Keywords: Medical dispute, Violence, Physician-patient relationship, Yi Nao, China, Healthcare reform

\section{Background}

Workplace violence against healthcare workers is a global issue receiving increasing attention [1-4]. This issue is particularly prevalent in China, so much so that it has become a severe public health challenge [5-7]. Between 2000 and 2014, there was an annual increase of $11 \%$ in the incidence of violence against medical staff [8]. Between 2000 and 2011, 124 cases of severe violence against healthcare workers occurred in Chinese hospitals, including 29 murders and 52 serious injuries [9].

Violence is not limited solely to acts of physical violence but can extend to verbal attacks as well. For example, verbal abuse from patients and relatives has contributed to significant mental stress among healthcare workers [10]. Hospital employees already face high levels of job-related stress and are at-risk for job-related burnout [11]. Thus, the combination of both physical attacks and verbal attacks, either actually carried out or feared, holds serious concern for China's healthcare workforce as they carry out their already stress-laden and critical role.

The Chinese word, "Yi Nao" (translated as "illegal disturbance and interruption of medical services"), contributes to this public health concern in contemporary China. Yi Nao has evolved so that organized gangs have become involved, seeking out perceived medical malpractice, and violently attacking healthcare providers [12]. Those patients who hire gangs may hope to gain financial compensation from hospitals for the perceived medical malpractice. The anger of the patients and their relatives, along with the threat to healthcare workers, has further exacerbated deteriorating patient-provider relationships and threatens normal functioning within the Chinese healthcare system [13, 14].

Many reasons are cited for this increase in violence against healthcare workers, including long waiting times [9], unrealistic expectations from patients (e.g., complete recovery after one or two visits) [15], limited legal channels for resolving medical disputes $[8,16]$, and an absence of legal penalties against this violence $[8,17]$. Thus, policymakers and others may have no simple solution to this growing and complex issue.
Even though violence might be the most extreme reaction, it is not always the response when medical disputes arise. Opportunities to pursue litigation exist, but research has shown that local courts are insufficiently equipped to handle these matters, leading to plaintiffs having to bring their cases to provincial or central courts to seek resolution, thereby adding extra layers of difficulty $[18,19]$. Thus, this may even serve to exacerbate this growing issue further. Given the challenges to a legal resolution, many patients chose to expose their negative experience of medical care to news or media outlets who may actively pursue such headline stories. Previous studies reported that numerous news reports were exaggerated and contributed to deteriorating patient-physician relationships [13]. Other alternatives to medical disputes, including complaints to hospital or healthcare authorities or outside mediation often fail to resolve disputes, because of a lack of adequate mechanisms in place to address patient complaints $[17,20]$.

While many systematic flaws and causes for medical disputes have been posited, one critical question remains: when patients or patients' families face a medical dispute, who are the most likely individuals to commit acts of violence against healthcare workers? In response to this gap, the primary aim of this study was to examine the characteristics of those who report being more likely to resort to violence or pursue other serious responses when facing a medical dispute. Those seeking to implement effective interventions that could help address violence in response to disputes should understand the characteristics of those that might be inclined to respond violently. This study would help enable them to carefully design interventions to prevent this behavior while maintaining regular medical services.

\section{Methods}

\section{Data collection and study participants}

Between July and August of 2014, 5714 inpatients and outpatients were recruited from 12 leading public hospitals in metropolitan areas across China. Hospitals were selected in five different provinces (Shandong, Jiangsu, Hubei, Henan, and Sichuan), providing some representation of eastern, central, and western regions of China. In 
each hospital, inpatients who were able to respond to the survey were included in the survey, while outpatients were asked to participate in waiting rooms. Trained surveyors provided the questionnaires to the participants. Patients were only included in the study if they consented to participate, were literate in Mandarin Chinese, and were coherent when filling out the survey. Almost everyone who was invited agreed to participate, while 20 to $30 \%$ did not complete the survey, with some variation among hospitals. Among all survey respondents, those who were born on or before 1999 were selected, thereby reaching a study sample size of 5556 .

\section{Study variables}

The dependent variable assessed in this study was the patient's self-reported response to a medical dispute. We developed the question for this study, asking: "assuming you are facing a medical dispute, what is your primary approach?" The options are listed below, with assigned severity from lowest to highest: (1) complaining to friends and relatives, (2) negotiating with the doctor, (3) complaining to the hospital or the health department, (4) negotiating with a third party ${ }_{a}$, (5) seeking legal help, (6) exposing the issue to the news/media, and (7) resorting to violence. Given the nature of this question, if the patients chose option 7 (resorting to violence), we assume it stands for Type II workplace violence as defined by The National Institute for Occupational Safety and Health $(\mathrm{NIOSH})[21,22]$, which is violence from customer or client.

We dichotomized the responses into the lower and higher level responses based on their seriousness. The options "complaining to friends and relatives," "negotiating with the doctor," and "complaining to the hospital or the health department" were categorized as lower-level responses. The higher-level response category included "negotiating with a third party," "seeking legal help," "exposing the issue to the news/media," and "resorting to violence," given these actions bring the dispute to an external entity or imply other relatively more severe outcomes. This dichotomization generated relatively balanced samples, with 55 and $45 \%$ for lower and higher level responses, respectively.

The independent variables were patients' opinions on healthcare quality, patient-provider interpersonal trust, and general life attitudes. This survey used the existing composite measures adapted from the Interpersonal Trust Scale (ITS) [23], Wake Forest Physician Trust Scale (WFPTS) [24] and SERVQUAL (Service Quality Scale) [25], to evaluate the quality of care [26] and patient-physician trust $[27,28]$. We also developed specific questions on participants' attitudes towards their life and health. General attitudes measures and standard scales measuring trust and quality all ranged from 1 to
5, with 1 as the worst (e.g., lowest trust, lowest satisfaction, etc.), and 5 as the best (e.g., highest perceived quality, most optimistic). Each survey also included standard questions on sex, year of birth, marital status, education level, occupation, rural or urban residence, insurance type, and the individuals' income level. Considering the possible impact from traveling distance and transportation difficulty, we designed a question in the survey asking whether patients were from the same county as the hospital they were seeking care in. The possible answers included the same county, out of the county, but within the province, and out of the province. Other general healthcare utilization questions included the type of services for which they sought care (inpatient or outpatient), previous experience with the hospital (having been to the very hospital or not), as well as their perception about healthcare quality received (1-worst, 5-best, Likert scale) and their trust towards this hospital and their physicians (1-worst, 5 best, Likert scale). These questions sought to investigate whether there were associations between healthcare utilization and their attitude when facing disputes.

\section{Data analyses}

Chi-squared tests and t-tests were used to describe bivariate relationships between the independent variables and responses to approaches when dealing with medical disputes in two categories (lower or higher severity). The responses for all independent variables were broken down by types of reactions to medical disputes, comparing lower-level to higher-level, as well as non-violent to violent responses.

We used two sets of multivariable logistic regression analyses to assess the potentially influential factors in patient responses to medical disputes. One used the binary outcome variable of higher vs. lower severity, while the other used violent vs. all other non-violent responses. Independent variables included demographic characteristics, socioeconomic status, and attitudes towards trust and service quality as separate sets of independent variables for the two regression models. Key demographic variables (age, sex, a first-time visitor or not, and inpatient or outpatient) were included in both models as controls regardless of their significance in bivariate analysis. Other variables that had $p<.10$ in the bivariate analyses were included in the regression analyses using a forward selection method. The significance level of 0.05 was used for the regression analyses. All analyses were conducted using SAS 9.4 (Cary, NC).

\section{Results}

\section{Categories of responses to medical disputes}

Table 1 describes the frequency distribution for participants' primary response to a medical dispute. Among 
Table 1 Frequencies of answers to the potential approaches for medical dispute

\begin{tabular}{|c|c|c|c|}
\hline Options when facing a medical dispute & Frequency & Percentage & Categorization \\
\hline Complaining to friends and relatives & 165 & $3.0 \%$ & \multirow{3}{*}{$\begin{array}{l}\text { Lower-level Response } \\
(N=3059 ; 55.1 \%)\end{array}$} \\
\hline Negotiating with the doctor & 1087 & $19.6 \%$ & \\
\hline Complaining to the hospital or the health department & 1807 & $32.5 \%$ & \\
\hline Negotiating with a third party & 413 & $7.4 \%$ & \multirow{5}{*}{$\begin{array}{l}\text { Higher-level Response } \\
(N=2497 ; 44.9 \%)\end{array}$} \\
\hline Seeking legal help & 1461 & $26.3 \%$ & \\
\hline Exposing to the news/media & 540 & $9.7 \%$ & \\
\hline Resorting to violence & 83 & $1.5 \%$ & \\
\hline Total & 5556 & $100.0 \%$ & \\
\hline
\end{tabular}

those with lower-level (less severe) responses, 165 individuals (overall 3\%) chose "complaining to friends and relatives," which may mean not taking any actions to resolve the medical dispute. In addition, about $20 \%$ of the respondents chose "negotiating with the doctor," and nearly $33 \%$ of the participants selected "complaining to the hospital or the health department," which was the most common response. For those with higher-level responses, over $26 \%$ of all participants picked "seeking legal help," $7 \%$ of the respondents would negotiate with a third party. A significant group of respondents also gave more serious responses, including "exposing to the news/media" (9.7\%) and "resorting to violence" (1.5\%).

\section{Bivariate analysis: sociodemographic characteristics, attitudes, and trust and quality scales}

Three thousand fifty-nine participants (55.1\%) reported lower-level (less severe) responses, and 2497 participants (44.9\%) reported higher-level (more severe) responses. Their sociodemographic information is shown in Table 2, along with bivariate analyses by (1) response severity level (lower vs. higher) and (2) violence vs. non-violence. The different categories of responses to medical disputes had variation in the distribution of sociodemographic characteristics.

Significant differences between a lower-level response and a higher-level response to medical disputes were found for marital status, education, travel distance, and rural-urban status. Compared to those who reported lower-level responses, participants reporting a higherlevel response were more likely to be married (versus not married, $p<.01)$, educated at the junior high school level or below (versus senior high school or equivalent or higher, $p<.05$ ), unemployed (versus employed, $p<.10$ ), traveling within the county (versus outside the county or province, $p<.05)$ and residing in a rural area (versus an urban area, $p<.01$ ).

For the comparison between those who chose nonviolent options $(n=5473)$ versus violent responses $(n=$ 83), statistically significant variations were found for characteristics including sex, age, income, and outpatient status. While the group reporting that they would pursue violent responses to medical disputes was small, those who disproportionally reported violence as a preferred option to disputes were more likely to be male $(p<.01)$, younger $(p<.10)$, reporting relatively higher income $(p<.10)$, and outpatients $(p<.05)$. Those who were born in the 1980s $(p<.10)$ and 1990s $(p<.10)$ reported a higher likelihood of pursuing violence as their primary response to a medical dispute. Individuals within the highest tier of income ( $>=\mathrm{CNY} 10,000$ per month) had a $7.2 \%$ share of the "resorting to violence" responses, but only $1.7 \%$ share of the non-violent response $(p<.10)$.

As shown in Table 3, the trust and quality scales showed statistically significant bivariate association with participants' primary response to a medical dispute, both in lower vs. higher level comparisons and in violence vs. non-violence response comparisons (all $p<.01$ ).

Those individuals who selected a higher-level response to medical disputes had lower trust scores from both physician trust (WFPTS) and interpersonal trust (ITS), as well as lower perceptions of service quality (SERVQUAL). Similar trends also appeared in the group selecting violence as a response to disputes, with lower scores $(p<.001)$ : WFPTS at 2.96 , ITS at 2.53 , and SERVQUAL at 3.36, comparing to $3.35,2.68$ and 3.68 in the nonviolent group, respectively. Participants who reported higher-level responses were less-satisfied with life than those who reported lower-level responses $(p<0.001)$. In addition, "satisfaction with life" $(p<.01)$, "perceived importance of health" $(p<.05)$, and "general optimism about life" scores $(p<.10)$ were significantly different among those would resort to violence versus others.

\section{Multivariate Logistic Regressions}

For comparisons between higher- and lower-levels of responses to a medical dispute, influential factors were travel distance, rural-urban status, satisfaction with life, and both trust scales in the multivariate analysis (Table 4). As relative travel distance increased (i.e., traveling outside of the county or province), patients' tendency to 
Table 2 Sociodemographic characteristics of participants by response to medical dispute

\begin{tabular}{|c|c|c|c|c|c|c|}
\hline Frequency (Column \%) & $\begin{array}{l}\text { Lower-level Response }(\boldsymbol{n}= \\
\text { 3059) }\end{array}$ & $\begin{array}{l}\text { Higher-level Response }(\boldsymbol{n}= \\
\text { 2497) }\end{array}$ & $p$ & $\begin{array}{l}\text { Non-violence }(\boldsymbol{n}= \\
\text { 5473) }\end{array}$ & $\begin{array}{l}\text { Violence }(\boldsymbol{n}= \\
83)\end{array}$ & $p$ \\
\hline$\overline{\text { Sex }}$ & & & & & & ** \\
\hline Female & $1667(54.5 \%)$ & $1342(53.7 \%)$ & & $2978(54.4 \%)$ & $31(37.3 \%)$ & \\
\hline Male & $1392(45.5 \%)$ & 1155 (46.3\%) & & 2495 (45.6\%) & $52(62.7 \%)$ & \\
\hline Birth Year & & & & & & $\dagger$ \\
\hline 1949 or before & $317(10.4 \%)$ & $258(10.3 \%)$ & & $568(10.4 \%)$ & $7(8.4 \%)$ & \\
\hline 1950-1959 & $292(9.5 \%)$ & $230(9.2 \%)$ & & $518(9.5 \%)$ & $4(4.8 \%)$ & \\
\hline 1960-1969 & $437(14.3 \%)$ & $322(12.9 \%)$ & & $751(13.7 \%)$ & $8(9.6 \%)$ & \\
\hline 1970-1979 & $570(18.6 \%)$ & $541(21.7 \%)$ & & $1094(20.0 \%)$ & $17(20.5 \%)$ & \\
\hline 1980-1989 & $957(31.3 \%)$ & 809 (32.4\%) & & $1732(31.6 \%)$ & $34(41.0 \%)$ & \\
\hline 1990-1999 & $486(15.9 \%)$ & $337(13.5 \%)$ & & $810(14.8 \%)$ & $13(15.7 \%)$ & \\
\hline Marital Status & & & $* *$ & & & \\
\hline Unmarried & $633(20.7 \%)$ & $448(17.9 \%)$ & & 1061 (19.4\%) & $20(24.1 \%)$ & \\
\hline Married & $2426(79.3 \%)$ & 2049 (82.1\%) & & 4412 (80.6\%) & $63(75.9 \%)$ & \\
\hline Education & & & * & & & \\
\hline Junior High School or Below & $1119(36.6 \%)$ & $981(39.3 \%)$ & & $2072(37.9 \%)$ & $28(33.7 \%)$ & \\
\hline $\begin{array}{l}\text { Senior High School or } \\
\text { equivalent }\end{array}$ & $871(28.5 \%)$ & 704 (28.2\%) & & $1550(28.3 \%)$ & $25(30.1 \%)$ & \\
\hline Junior College or Higher & 1069 (34.9\%) & $812(32.5 \%)$ & & 1851 (33.8\%) & $30(36.1 \%)$ & \\
\hline Unemployed & $806(26.3 \%)$ & $728(29.2 \%)$ & $\dagger$ & 1514 (27.7\%) & $20(24.1 \%)$ & \\
\hline Travel distance measure & & & * & & & \\
\hline Short-distance & $2439(79.7 \%)$ & $2048(82.0 \%)$ & & 4419 (80.7\%) & 68 (81.9\%) & \\
\hline Mid-distance & $406(13.3 \%)$ & 300 (12.0\%) & & $695(12.7 \%)$ & $11(13.3 \%)$ & \\
\hline Long-distance & $214(7.0 \%)$ & $149(6.0 \%)$ & & 359 (6.6\%) & $4(4.8 \%)$ & \\
\hline Rural & 1665 (54.4\%) & 1449 (58.0\%) & $* *$ & 3067 (56.0\%) & 47 (56.6\%) & \\
\hline Urban & $1394(45.6 \%)$ & $1048(42.0 \%)$ & & $2406(44.0 \%)$ & $36(43.4 \%)$ & \\
\hline Monthly Income (CNY) & & & & & & $\dagger$ \\
\hline$<1000$ & $636(20.8 \%)$ & $552(22.1 \%)$ & & $1170(21.4 \%)$ & $18(21.7 \%)$ & \\
\hline $1000 \sim 1999$ & $676(22.1 \%)$ & $560(22.4 \%)$ & & $1220(22.3 \%)$ & $16(19.3 \%)$ & \\
\hline $2000 \sim 2999$ & $733(24.0 \%)$ & 617 (24.7\%) & & $1336(24.4 \%)$ & $14(16.9 \%)$ & \\
\hline $3000 \sim 4999$ & $709(23.2 \%)$ & $523(20.9 \%)$ & & $1212(22.1 \%)$ & $20(24.1 \%)$ & \\
\hline $5000 \sim 9999$ & $257(8.4 \%)$ & $193(7.7 \%)$ & & $441(8.1 \%)$ & $9(10.8 \%)$ & \\
\hline$>=10,000$ & $48(1.6 \%)$ & $52(2.1 \%)$ & & $94(1.7 \%)$ & $6(7.2 \%)$ & \\
\hline Inpatient & $1687(55.1 \%)$ & $1392(55.7 \%)$ & & $3044(55.6 \%)$ & 35 (42.2\%) & * \\
\hline Outpatient & $1369(44.8 \%)$ & 1105 (44.3\%) & & 2426 (44.3\%) & 48 (57.7\%) & \\
\hline
\end{tabular}

Mantel-Haenszel Chi-Square Test $p$-value indicator: " ${ }^{\prime \prime} p<.10,{ }^{*} p<.05,{ }^{* *} p<.01,{ }^{* * *} p<.001$. This test examines the alternative hypothesis that there is a linear association between the two variables. The item "travel distance measure" was derived from a question asking patients' hometown locations relative to the hospital location. Three options were provided in the multiple-choice question: within the same county, outside of the county within the same province, and outside of the province. These three options were designated "short-distance," "mid-distance," and "long-distance," respectively

report a higher-level response decreased, but no statistical significance was found. Rural residents were more likely to select the higher-level responses when compared to urban residents $(\mathrm{OR}=1.167, p<.05)$. As trust scores (both WFPTS and ITS) increased, the likelihood of reporting higher-level responses to a medical dispute decreased (WFPTS: OR $=0.808, p<.001$; ITS: OR = $0.796, p<.01)$.
For comparisons between violent and non-violent responses to medical disputes, influential factors included sex and income (Table 4). Patients who reported higher levels of life satisfaction were also more likely to report "resorting to violence" when facing a medical dispute $(\mathrm{OR}=1.404, p<.05)$. Females were less likely to select violence as an option than males $(\mathrm{OR}=0.551, p<.05)$. Compared to a monthly income of CNY $2000 \sim 2999$, 
Table 3 General attitudes and standard scale measures by response to medical dispute

\begin{tabular}{|c|c|c|c|c|c|c|}
\hline Mean (Standard Deviation) & $\begin{array}{l}\text { Lower-level Response }(\boldsymbol{n}= \\
\text { 3059) }\end{array}$ & $\begin{array}{l}\text { Higher-level Response }(\boldsymbol{n}= \\
\text { 2497) }\end{array}$ & $p$ & $\begin{array}{l}\text { Non-violence }(\boldsymbol{n}= \\
5473)\end{array}$ & $\begin{array}{l}\text { Violence }(\boldsymbol{n}= \\
83)\end{array}$ & $p$ \\
\hline \multicolumn{7}{|l|}{ Attitudes } \\
\hline Satisfaction with Life & $3.52(0.77)$ & $3.44(0.79)$ & $* * *$ & $3.49(0.78)$ & $3.16(0.90)$ & $* *$ \\
\hline $\begin{array}{l}\text { Perceived Importance of } \\
\text { Health }\end{array}$ & $4.10(0.74)$ & $4.10(0.74)$ & & $4.10(0.74)$ & $3.92(0.83)$ & $*$ \\
\hline General Optimism about Life & $3.80(0.72)$ & $3.78(0.74)$ & & $3.79(0.73)$ & $3.65(0.82)$ & $\dagger$ \\
\hline \multicolumn{7}{|l|}{ Trust and Quality Scales } \\
\hline WFPTS & $3.39(0.65)$ & $3.29(0.68)$ & $* * *$ & $3.35(0.67)$ & $2.96(0.67)$ & $* * *$ \\
\hline ITS & $2.69(0.36)$ & $2.65(0.37)$ & $* * *$ & $2.68(0.36)$ & $2.53(0.44)$ & ** \\
\hline SERVQUAL & $3.70(0.57)$ & $3.64(0.57)$ & $* * *$ & $3.68(0.57)$ & $3.36(0.65)$ & *** \\
\hline
\end{tabular}

"†" $p<.10,{ }^{*} p<.05,{ }^{* *} p<.01,{ }^{* * *} p<.001$. All items in this table were measured on a scale from 1 to 5 , with 1 as the worst state of being, and 5 as the best state of being. The $p$-values in Table 3came from the two-sample t-test. [Abbreviations] WFPTS Wake Forest Physician Trust Scale, ITS Interpersonal Trust Scale, SERVQUAL Service Quality Scale

the highest tier incomes ( $>=\mathrm{CNY} 10,000)$ were more likely to select violence $(\mathrm{OR}=3.712, p<.05)$.

\section{Discussion}

This study adds a critical assessment, to the insufficiently studied existing literature, of factors associated with hospital violence and other extreme responses related to medical disputes. Further, we provide a unique patient perspective from a low-to-middle income country experiencing major policy-related changes within the health care system in recent years, namely health care financing reform $[26,29,30]$. Apart from the influence of trust of physicians and perceived healthcare quality in bivariate analysis, we were able to find associations between sociodemographic characteristics and more extreme responses related to medical disputes, including violence.

This study highlights several underlying factors related to more severe responses to medical disputes. Those who resided in rural areas tended to choose a more severe type of response when faced with a medical dispute. Some rural respondents may have limited knowledge or experience related to non-violent or other less severe alternatives when facing a medical dispute or otherwise negative experience. Those with the highest income had a higher likelihood of "resorting to violence." Providing informal payments to physicians in the forms of red envelop or gifts is not uncommon in Chinese culture [31]. Further, some research argues that the association between health inequity and poverty may affect the healthcare experiences between low-income and high-income patients [32]. Future research is needed to study the impact of income and provide a more theoretical framework explaining the violence tendency in different income groups.

In this study, we also found that participants who reported greater satisfaction with their life were more likely to report violence as their primary response to a medical dispute. This paradoxical result suffers from selection bias and should be interpreted with caution. Considering the skewness of the responses to the "life satisfaction" question (more than $80 \%$ answering "satisfied" or "ordinary") and only $1.5 \%(n=83)$ reporting 'resorting with violence, it may not be unusual to observe more individuals reporting "violence" in the "satisfied" or "ordinary" categories than that in the "dissatisfied" or "very dissatisfied" categories.

While the supply side shortage remains a possible cause of violence against healthcare workers, patients' expectations could be another critical factor. An outcome from a tendency in patients to seek care, early on, at the hospital level is that patients have unrealistic expectations of the efficiency of secondary and tertiary care providers. Examples of these unrealistic expectations include receiving all the medications they want even if not medically indicated, obtaining an immediate and complete recovery, or a considerable improvement, all from a single, long-awaited visit [13]. When the prescription, diagnosis, or outcome is different from their expectations, patients and their relatives could perceive that as medical malpractice and quickly become anxious or even angry.

The current study also found that patients' trust in their physicians were strongly associated with their selected primary reaction in a medical dispute. Challenges within the Chinese healthcare system seem to be related to the underlying factor associated with patients' responses to engage in violence when facing a medical dispute. Since the commercialization of medicine in 1985, public hospitals in China have not had consistent government funding, so they may have sought other approaches (e.g., over-prescribing medication and other treatments) to offset the costs [6]. While patients bear the burden of paying higher prices for medical services that are exceeding the current inflation rate, healthcare workers, especially physicians, are getting salaries far less 
Table 4 Logit regression model on reactions towards medical dispute (95\% Cl)

\begin{tabular}{|c|c|c|c|c|}
\hline & Model 1: Higher vs. LC & Level Response & Model 2: Violer & Other Response \\
\hline Sociodemographics & OR & $95 \% \mathrm{Cl}$ & OR & $95 \% \mathrm{Cl}$ \\
\hline Female (ref: Male) & 0.988 & $(0.881,1.109)$ & $0.551 *$ & $(0.339,0.894)$ \\
\hline Birth Year & (Ref: 1949 or before) & & & \\
\hline 1950-1959 & 0.920 & $(0.719,1.176)$ & 0.571 & $(0.164,1.984)$ \\
\hline 1960-1969 & 0.891 & $(0.709,1.120)$ & 0.839 & $(0.295,2.390)$ \\
\hline 1970-1979 & 1.146 & $(0.921,1.425)$ & 1.139 & $(0.448,2.897)$ \\
\hline 1980-1989 & 1.027 & $(0.827,1.277)$ & 1.242 & $(0.509,3.028)$ \\
\hline 1990-1999 & 0.977 & $(0.744,1.283)$ & 0.958 & $(0.343,2.678)$ \\
\hline Marital Status & (Ref: unmarried) & & & \\
\hline Married & 1.089 & $(0.915,1.296)$ & 0.890 & $(0.473,1.678)$ \\
\hline Travel Distance Measure & (Ref: Short-distance) & & & \\
\hline Mid-distance & $0.852 \dagger$ & $(0.719,1.010)$ & (Not included) & \\
\hline Long-distance & 0.833 & $(0.662,1.047)$ & & \\
\hline Rural (ref: Urban) & $1.167^{*}$ & $(1.027,1.326)$ & (Not included) & \\
\hline Education & (Ref: $<=$ Junior High) & & & \\
\hline Senior High School or equivalent & 0.934 & $(0.806,1.084)$ & (Not included) & \\
\hline Junior College or Higher & 0.910 & $(0.771,1.074)$ & & \\
\hline Unemployed (ref: employed) & 1.056 & $(0.923,1.209)$ & (Not included) & \\
\hline Monthly Income (CNY) & (Ref: 2,000 2999) & & & \\
\hline$<1000$ & (Not included) & & $1.905+$ & $(0.904,4.017)$ \\
\hline $1000 \sim 1999$ & & & 1.504 & $(0.722,3.134)$ \\
\hline $3000 \sim 4999$ & & & 1.341 & $(0.667,2.697)$ \\
\hline $5000 \sim 9999$ & & & 1.540 & $(0.648,3.658)$ \\
\hline$>=10,000$ & & & $3.712^{*}$ & $(1.328,10.381)$ \\
\hline \multicolumn{5}{|l|}{ Experience } \\
\hline First-time visitor (ref: non-1 st-timer) & 1.004 & $(0.876,1.150)$ & 0.868 & $(0.505,1.490)$ \\
\hline Inpatient (ref: Outpatient) & 1.047 & $(0.926,1.185)$ & 0.780 & $(0.926,1.185)$ \\
\hline \multicolumn{5}{|l|}{ Attitudes } \\
\hline Satisfaction with Life & $1.066+$ & $(0.990,1.148)$ & $1.404^{*}$ & $(1.031,1.911)$ \\
\hline Perceived Importance of Health & (Not included) & & 1.206 & $(0.901,1.616)$ \\
\hline Optimism Measure & (Not included) & & 0.908 & $(0.648,1.273)$ \\
\hline \multicolumn{5}{|l|}{ Trust and Quality Scales } \\
\hline WFPTS & $0.808^{* * *}$ & $(0.720,0.905)$ & 0.719 & $(0.460,1.123)$ \\
\hline ITS & $0.796^{* *}$ & $(0.678,0.936)$ & 0.638 & $(0.351,1.159)$ \\
\hline SERVQUAL & 1.002 & $(0.881,1.139)$ & 0.675 & $(0.421,1.084)$ \\
\hline
\end{tabular}

"†" $p<.10,{ }^{*} p<.05,{ }^{* *} p<.01,{ }^{* * *} p<.001$. Certain variables were included in the multivariate regression regardless of their statistical significance in bivariate analysis. These variables are age, gender, marital status, a first-time visitor or not, inpatient or outpatient. Other covariates were "not included" if they were not statistically significant at $90 \%$ confidence level ( $p>=.10$, as indicated in the table). The odds ratios (O.R.s) here are adjusted odds ratios (AORs), meaning that they are controlled for other predictors in the model

than their counterparts in other countries. While patients may have a negative experience within the healthcare system, providers are also facing double challenges of low pay and high workload [33]. Further, biased media reports and distorted social norms are negatively affecting healthcare workers, as news reports typically focus on negative events in which patients are characterized as victims from medical malpractice $[8$, 34]. These factors likely contribute to deteriorating relationships between patients and healthcare workers.

Studying violence against healthcare workers is critical because this violence could have many detrimental effects, which could further harm the patient-provider relationship and generate a higher likelihood of future 
violence or extreme behaviors. Violence against medical personnel can increase the psychological stress of healthcare workers $[35,36]$, and drive individuals away from the medical profession [33], further reducing the healthcare workforce and making it harder to meet patients' demands. With one-fifth of the world's population (1.4 billion) residing in China [37], the available workforce in the healthcare sector is far lower when compared to other countries. In 2014, China had 1724 physicians per 1 million population, while the United States had 2568, and Cuba had 7519 as the world's highest [38]. Furthermore, patients in China can seek secondary and tertiary care providers without a referral from primary care providers. Thus, large public hospitals that house many of the secondary and tertiary providers often face crowds far beyond their limited capacity, leading to extremely long waiting times [39]. This no-referral-needed system further tilts the balance between supply and demand in the healthcare delivery system and worsens the issue of workforce shortages in China. The possible link between workplace violence, high demand, and understaffing in China could be impactful, as this association has already been demonstrated in some European studies [3, 22]. Further-more, given legal channels for resolving confusion or anxiety are sometimes lacking and there is difficulty in implementing penalties for violence [17], verbally or physically attacking the healthcare worker becomes a way to release patients' anger [12, 16]. That said, policies aimed at promoting the role of general practitioners in primary care have been suggested as a way to bring about positive change to the existing system through improved access to care [40].

Financial challenges within the healthcare system, such as physicians not receiving sufficient salary and patients paying too much for medical care, could also be contributing to the worsening patient-physician relationship and may ultimately lead to patients' extreme actions [6, 33]. Further, current interventions are both limited in number and effectiveness. Police departments have been sending more armed security guards to at-risk hospitals, while multiple studies argue that this does not improve weak provider-patient trust and, in fact, maybe more detrimental than doing nothing at all $[7,8]$. Regulatory agencies are mandating price controls over medical services, which could make it difficult for hospitals to meet rising costs. As the economic pressure accumulates on both the providers' and the patients' sides, the gap between patient expectation and healthcare services quality and cost may be diverging further. Therefore, reforms at the national level, targeted at reducing economic burdens on the entire healthcare delivery system, are essential to improving the patient-provider relationship and reducing the incidence of violence and other extreme responses when medical disputes arise. Other reforms may also hold promise. For example, the National Hierarchical Medical System, among other things, includes policies relating to promoting the role of general practitioners. However, past research has noted a relatively limited awareness of this policy and the role of general practitioners [40]. Thus, providing greater awareness of the role of general practitioners and the National Hierarchical Medical System has been suggested [40] as a means of addressing health care access issues, to an extent, given the relatively underutilized primary care settings throughout China.

\section{Limitations}

This study has limitations in generalizability and from self-report. Even though the survey received more than 5000 responses, the findings cannot be generalized to all patients in China, given its geographic and demographic diversity. Moreover, this survey only included respondents in large public hospitals because of their large capacity and diversity in patients seeking care at these facilities, rather than primary care facilities or private hospitals. The generalizability of this study is also limited in that the survey question did not specify which healthcare providers (e.g., physicians, nurses, administrative staff, etc.) were the potential recipients of violence. While the lack of specific detail about which healthcare providers were potential targets may encourage some respondents to provide a relatively honest answer, further studies by types of healthcare providers are necessary.

Another limitation of this study is reporting bias. First, participants recruited in this study were able to read and speak Mandarin, which was necessary given the survey language (Mandarin). This may have led to the recruitment of those with at least minimal literacy needed to complete the survey and speak with study staff. As such, those who did not read or speak Mandarin or those who were illiterate may have been underrepresented holding potential implications as one's level of literacy may be associated with aggressive tendencies [41, 42]. Second, realistically, patients may be unlikely to report their tendency towards violence when responding to a survey, especially when the survey was conducted in the very hospital where they seek care. Therefore, this study might have underestimated the number of patients whose primary reaction to a medical dispute is violence. The low number of patients responding "resorting to violence" ( $n=83$ out of 5556) in this study also limits our power to detect possible factors associated with a tendency towards violence.

In addition, given practical limitations in terms of available resources (e.g., funding, time), we were unable to carry out a mixed-method approach (e.g., purposively sampling from those reporting a tendency towards violence) that would have complemented the survey 
findings with more in-depth interviews. Future research should consider the benefits and limitations of using qualitative interviews for potentially sensitive questions and prepare appropriate methods to address potential bias in reporting.

\section{Conclusions}

This is one of the first studies investigating the impact of patient characteristics on their response to medical disputes, especially regarding the issue of violence against healthcare workers in China. We suggested a model in examining the possibility of resorting to higher-level reactions to medical disputes, which include socioeconomic status, perceived healthcare quality, and potential risks of extreme behaviors. Although further investigation is necessary to provide reliable guidance, those seeking to implement effective and targeted interventions should focus on these indicators for possible extreme behaviors related to medical disputes. Hospitals should continue to improve their quality of care and trust between patients and healthcare workers. Populations with relatively lower socioeconomic status may need additional assistance so that they may meet their basic needs for healthcare, and patients feel greater satisfaction with their health care providers and the health care services they receive.

As shown in the existing literature, critical stakeholders at organizational and state levels, including but not limited to legal administration and enforcement agencies, must be involved in preventing and addressing violence towards health care workers [43]. The legal system should develop appropriate penalties for individuals who have violent behaviors towards healthcare workers. The active participation of all aspects of society could reduce the incidence of extreme reactions towards medical disputes and prevent them from developing into Yi Nao. Aggression and violence against healthcare workers are prevalent in other countries without Yi Nao as well $[4,44]$, and as such, stakeholders in China may be able to learn from other examples of how to address this issue with a systematic reform in the healthcare framework $[35,36]$. If the tense relationship between healthcare providers and patients can be improved, psychological pressures on healthcare workers may be alleviated, and China will have a much more sustainable healthcare workforce, which is critical to sustainably improve healthcare service delivery.

\section{Abbreviations}

CDC: Centers for Disease Control and Prevention; ITS: Interpersonal Trust Scale; NIOSH: The National Institute for Occupational Safety and Health; OR: Odds Ratio; WFPTS: Wake Forest Physician Trust Scale; SERVQUAL: Service Quality Scale

\section{Acknowledgments}

We sincerely appreciate the fieldwork of survey data collection done by students at the School of Management, Jiangsu University, China.

\section{Authors' contributions}

WW designed the patient survey and conducted primary data collection with colleagues from Jiangsu University. YD conceived of the research idea. YD, WW, DW, and JM developed the analysis plan. SL HZ and ST advised on methodological design. YD led the data analysis and interpretation, with assistance from DW and JM, YD led the drafting of the manuscript, with significant contributions from DW, JM, SL, and ST. All authors read and approved the final version of the manuscript.

\section{Authors' information}

$\mathrm{JM}$, as the corresponding author in English language, oversees the design and performance of this study. He is internationally recognized for his research in social-ecological approaches to promote health. He has served as President of the American Academy of Health Behavior and Honorary Secretary of the Asia-Pacific Academic Consortium for Public Health. This study is a close collaboration between Jiangsu University and Texas A\&M University made possible by J.M. inviting W.W. to serve as a visiting professor at Texas A\&M University. WW is the corresponding author in the Chinese language and served as principal investigator on the parent study.

\section{Funding}

This work was supported by the National Natural Science Foundation of China (Grant No.71673121 and No.71373102), the Research Innovation Program for College Graduates of Jiangsu Province (Grant No. KYZZ_0288); and Jiangsu Government Scholarship for Overseas Studies (Grant No. JS2016-099). The funding agencies had no role in the design of the study, collection, analysis, interpretation of the data, or writing the manuscript.

\section{Availability of data and materials}

The datasets generated and/or analyzed during the current study are not publicly available due to data protection programs administered by the National Science Foundation of China but are available from the corresponding author on reasonable request.

\section{Ethics approval and consent to participate}

The Ethics Committee of the School of Management at Jiangsu University approved the collection of data used in this study. Written consent was obtained from each participant in the study. Only participants who agreed to participate in the survey were given the questionnaire to complete. The Texas A\&M University Institutional Review Board (IRB) determined secondary analyses of these data (existing at the time of these analyses) was not human subject research (December 14, 2017) and thus exempt from full-IRB review by Texas A\&M University.

\section{Consent for publication}

Not Applicable.

\section{Competing interests}

The authors declare that they have no competing interests.

\section{Author details}

'Division of Public Health Sciences, Hutchinson Institute for Cancer Outcome Research (HICOR), Fred Hutchinson Cancer Research Center, Seattle, WA 98109, USA. ${ }^{2}$ Data Generation and Observational Studies, Bayer Healthcare U.S. LLC, Whippany, NJ 07981, USA. ${ }^{3}$ Department of Public Administration, Law School, Shantou University, Shan-Tou 515063, People's Republic of China. ${ }^{4}$ Department of Health Policy and Management, School of Public Health, Texas A\&M University, College Station, TX 77843, USA. ${ }^{5}$ Center for Population Health and Aging, Texas A\&M University, College Station, TX 77843 , USA. ${ }^{6}$ Department of Health Management and Informatics, University of Central Florida, Orlando, FL 32816, USA. Disability, Aging, and Technology Cluster Initiative, University of Central Florida, Orlando, FL 32816, USA. ${ }^{8}$ Department of Environmental and Occupational Health, School of Public Health, Texas A\&M University, College Station, TX 77843, USA. ${ }^{\text {SSouthwest }}$ Rural Health Research Center, Texas A\&M University, College Station, TX 77843 , USA. 
Received: 7 February 2019 Accepted: 12 March 2020

Published online: 26 March 2020

\section{References}

1. Gates DM. The epidemic of violence against healthcare workers. Occup Environ Med. 2004;61:649-50.

2. Kuehn BM. Violence in health care settings on rise. JAMA. 2010;304(5):511-2. https://doi.org/10.1001/jama.2010.1010.

3. Magnavita N, Heponiemi T. Violence towards health care workers in a Public Health Care Facility in Italy: A repeated cross-sectional study. BMC Health Serv Res. 2012;12(1):108.

4. Franz S, Zeh A, Schablon A, Kuhnert S, Nienhaus A. Aggression and violence against health care workers in Germany - a cross sectional retrospective survey. BMC Health Serv Res. 2010;10:51.

5. Anon. Chinese doctors are under threat. Lancet. 2010;376(9742):657. https:// doi.org/10.1016/S0140-6736(10)61315-3.

6. Zhang $X$, Sleeboom-Faulkner M. Tensions between medical professionals and patients in mainland China. Camb Q Healthc Ethics. 2011;20(3):458-65.

7. Yang T, Zhang H, Shen F, Li JW, Wu MC. Appeal from Chinese doctors to end violence. Lancet. 2013;382(9906):1703-4. https://doi.org/10.1016/S01406736(13)62401-0

8. Yao S, Zeng Q, Peng M, Ren S, Chen G, Wang J. Stop violence against medical workers in China. J Thorac Dis. 2014;6(6):141-5.

9. Hesketh T, Wu D, Mao L, Ma N. Violence against doctors in China. BM 2012;345(sep07 1):e5730. https://doi.org/10.1136/bmj.e5730.

10. Shi J, Wang S, Zhou P, Shi L, Zhang Y, Bai F, et al. The frequency of patientinitiated violence and its psychological impact on physicians in China: a cross-sectional study. PLoS One. 2015;10(6):1-17.

11. Chou LP, Li CY, Hu SC. Job stress and burnout in hospital employees: comparisons of different medical professions in a regional hospital in Taiwan. BMJ Open. 2014;4(2):1-7.

12. Jiao M, Ning N, Li Y, Gao L, Cui Y, Sun H, et al. Workplace violence against nurses in Chinese hospitals: a cross-sectional survey. BMJ Open. 2015;5(3):1-10.

13. He AJ, Qian J. Explaining medical disputes in Chinese public hospitals: the doctor-patient relationship and its implications for health policy reforms. Health Econ Policy Law. 2016;11(4):359-78.

14. Tucker JD, Cheng Y, Wong B, Gong N, Nie JB, Zhu W, et al. Patient-physician mistrust and violence against physicians in Guangdong Province, China: A qualitative study. BMJ Open. 2015:5(10):e008221.

15. An J. Which future for doctors in China? Lancet. 2013;382(9896):936-7 Available from: http://www.sciencedirect.com/science/article/pii/S0140673613619285.

16. Wu D, Wang $Y$, Lam KF, Hesketh $T$. Health system reforms, violence against doctors and job satisfaction in the medical profession: A cross-sectional survey in Zhejiang Province, Eastern China. BMJ Open. 2014;4(12). https:// doi.org/10.1136/bmjopen-2014-006431.

17. Zhao L, Zhang X-Y, Bai G-Y, Wang Y-G, Jiang Y, Ying $X$, et al. Violence against doctors in China. Lancet. 2014;384:744-5.

18. Peerenboom R, He X. Dispute resolution in China: patterns, causes and prognosis. East Asia Law Rev. 2009;4(1):1-61.

19. Liebman BL. Malpractice mobs: medical dispute resolution in China. Columbia Law Rev. 2013;113(1):181-264

20. Zhao M. Evaluation of the third-party mediation mechanism for medical disputes in China. Med Law. 2011;30(3):401-15.

21. CDC-NIOSH. NIOSH-WPVHC-Workplace Violence Types. Centers for Disease Control and Prevention. 2013 [cited 2020 Feb 13]. Available from: https:// wwwn.cdc.gov/WPVHC/Course.aspx/Slide/Unit1_5.

22. Nowrouzi-Kia B, Chai E, Usuba K, Nowrouzi-Kia B, Casole J. Prevalence of type ii and type iii workplace violence against physicians: a systematic review and meta-analysis. Int J Occup Environ Med. 2019;10(3):99-110.

23. Rotter JB. A new scale for the measurement of interpersonal trust. J Pers 1967;35(4):651-65

24. Hall MA, Zheng B, Dugan E, Camacho F, Kidd KE, Mishra A, et al. Measuring Patients's trust in their primary care providers. Med Care Res Rev. 2002:59(3): 293-318 Available from: http://www.ncbi.nlm.nih.gov/pubmed/12205830; \%0Ahttp://journals.sagepub.com/doi/10.1177/1077558702059003004; \%0Afile:///C:/Users/kellynum/Desktop/hall2002.pdf.

25. Parasuraman A, ZeithamI VA, Berry LL. SERVQUAL: a multiple-item scale for measuring consumer perceptions of service quality. J Retail. 1988;64(1):5-6.

26. Lee $S$, Wang W, Washburn DJ, Shi H, Yu Y, Du Y, et al. Effect of the treatment-before-deposit policy on trust in physicians and perceived service quality among patients in 12 hospitals in China. Int J Health Plann Manage. 2018;33:1110-20. https://doi.org/10.1002/hpm.2592.

27. Dong E, Liang Y, Liu W, Du X, Bao Y, Du Z, et al. Construction and validation of a preliminary Chinese version of the wake forest physician trust scale. Med Sci Monit. 2014;20:1142-50 Available from: http://www.medscimonit. com/abstract/index/idArt/889992.

28. Wang W, Zhang H, Washburn DJ, Shi H, Chen Y, Lee S, et al. Factors influencing trust towards physicians among patients from 12 hospitals in China. Am J Health Behav. 2018:42(6):19-30. https://doi.org/10.5993/AJHB.42.6.3.

29. Meng Q, Xu K. Progress and challenges of the rural cooperative medical scheme in China. Bull World Health Organ. 2014;92(6):447-51 Available from: http://www.who.int/entity/bulletin/volumes/92/6/13-131532.pdf.

30. Su M, Zhou Z, Si Y, Wei X, Xu Y, Fan X, et al. Comparing the effects of China's three basic health insurance schemes on the equity of healthrelated quality of life: using the method of coarsened exact matching. Health Qual Life Outcomes. 2018;16(1):1-12.

31. Chiu YC, Smith KC, Morlock L, Wissow L. Gifts, bribes and solicitions: print media and the social construction of informal payments to doctors in Taiwan. Soc Sci Med. 2007;64(3):521-30.

32. Sun X, Rehnberg C, Meng Q. How are individual-level social capital and poverty associated with health equity? A study from two Chinese cities. Int J Equity Health. 2009:8:1-13.

33. Pan $Y$, Yang $X$, He JP, Gu YH, Zhan XL, Gu HF, et al. To be or not to be a doctor, that is the question: a review of serious incidents of violence against doctors in China from 2003-2013. J Public Health. 2015;23(2):111-6.

34. Sun J, Liu S, Liu Q, Wang Z, Wang J, Hu CJ, et al. Impact of adverse media reporting on public perceptions of the doctor-patient relationship in China: an analysis with propensity score matching method. BMJ Open. 2018;8(8): e022455. https://doi.org/10.1136/bmjopen-2018-022455.

35. Magnavita N. The exploding spark: workplace violence in an infectious disease hospital - a longitudinal study. Biomed Res Int. 2013;2013. https:// doi.org/10.1155/2013/316358.

36. Magnavita N. Workplace violence and occupational stress in healthcare workers: a chicken-and-egg situation-results of a 6-year follow-up study. J Nurs Scholarsh. 2014:46(5):366-76.

37. World Population Review. 2018 World Population by Country (Live). 2018 [cited 2018 Nov 8]. Available from: http://worldpopulationreview.com/.

38. WHO. Global Health Observatory Data Repository: World Health Organization; 2014. [cited 2018 Nov 7]. Available from: http://apps.who.int/ gho/data/node.main. A1444?lang=en\&showonly=HWF.

39. Sun J, Lin Q, Zhao P, Zhang Q, Xu K, Chen H, et al. Reducing waiting time and raising outpatient satisfaction in a Chinese public tertiary general hospital-an interrupted time series study. BMC Public Health. 2017;17(1):1-11.

40. Liu X, Hou Z, Towne SD, He M, Tan A, Jiang D, et al. Knowledge, attitudes, and practices related to the establishment of the National Hierarchical Medical System (NHMS) among outpatients in Chinese tertiary hospitals. Medicine (Baltimore). 2018;97(35):e11836.

41. Davis TC, Byrd RS, Arnold CL, Auinger P, Bocchini JA. Low literacy and violence among adolescents in a summer sports program. J Adolesc Health. 1999;24(6):403-11 [cited 2020 Feb 28]; Available from: https://www. sciencedirect.com/science/article/abs/pii/S1054139X98001487.

42. Doctoroff GL, Greer JA, Arnold DH. The relationship between social behavior and emergent literacy among preschool boys and girls. J Appl Dev Psychol. 2006;27(1):1-13 [cited 2020 Feb 28]. Available from: https://www. sciencedirect.com/science/article/pii/S0193397305001097.

43. Nowrouzi-Kia B, Isidro R, Chai E, Usuba K, Chen A. Antecedent factors in different types of workplace violence against nurses: a systematic review. Aggress Violent Behav. 2019;44:1-7. https://doi.org/10.1016/j.avb.2018.11.002.

44. Schablon A, Wendeler D, Kozak A, Nienhaus A, Steinke S. Prevalence and consequences of aggression and violence towards nursing and care staff in Germany_A survey. Int J Environ Res Public Health. 2018:15(6):1274 [cited 2020 Feb 28]. Available from: http://www.mdpi.com/1660-4601/15/6/1274.

\section{Publisher's Note}

Springer Nature remains neutral with regard to jurisdictional claims in published maps and institutional affiliations. 